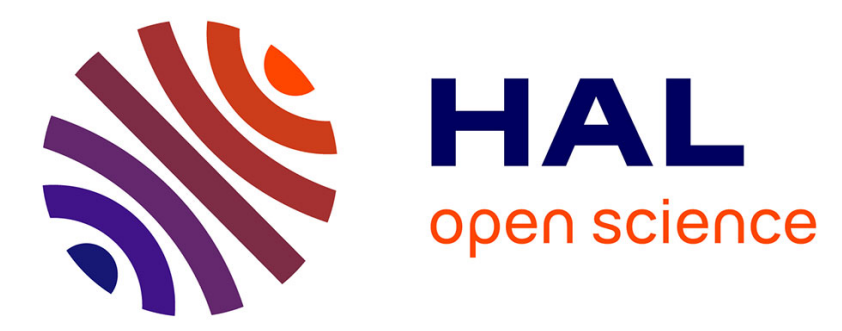

\title{
Elucidation of the Two-step Damage Formation Process of Latent Tracks in Poly(allyl diglycol carbonate), PADC: Role of Secondary Low-energy Electrons
}

\author{
Tamon Kusumoto, Michel Fromm, Pierre Cloutier, Andrew D Bass, Léon
} Sanche, Rémi Barillon, Tomoya Yamauchi

\section{To cite this version:}

Tamon Kusumoto, Michel Fromm, Pierre Cloutier, Andrew D Bass, Léon Sanche, et al.. Elucidation of the Two-step Damage Formation Process of Latent Tracks in Poly(allyl diglycol carbonate), PADC: Role of Secondary Low-energy Electrons. Journal of Physical Chemistry C, 2018, 122 (36), pp.2105621061. 10.1021/acs.jpcc.8b05341 . hal-03559895

\section{HAL Id: hal-03559895 \\ https://hal.science/hal-03559895}

Submitted on 7 Feb 2022

HAL is a multi-disciplinary open access archive for the deposit and dissemination of scientific research documents, whether they are published or not. The documents may come from teaching and research institutions in France or abroad, or from public or private research centers.
L'archive ouverte pluridisciplinaire HAL, est destinée au dépôt et à la diffusion de documents scientifiques de niveau recherche, publiés ou non, émanant des établissements d'enseignement et de recherche français ou étrangers, des laboratoires publics ou privés. 
Elucidation of the Two-step Damage Formation Process of Latent Tracks in Poly(allyl diglycol carbonate), PADC: Role of Secondary Low-energy Electrons

Tamon Kusumoto ${ }^{\mathrm{a}}$, Michel Fromm*b, Pierre Cloutier ${ }^{\mathrm{c}}$, Andrew D Bass ${ }^{\mathrm{c}}$, Léon Sanche ${ }^{\mathrm{c}}$, Rémi Barillon ${ }^{\mathrm{d}}$, Tomoya Yamauchi ${ }^{\mathrm{e}}$

a Radiation Measurement Research Team, National Institute of Radiological Sciences, National Institutes for Quantum and Radiological Science and Technology, 4-9-1 Anagawa, Inage-ku, 263-8555 Chiba, Japan

${ }^{\mathrm{b}}$ UMR CNRS 6249 Chrono-Environnement, Université de Bourgogne-Franche-Comté, 16 Route de Gray, F-2530 Besançon Cedex, France

${ }^{\circ}$ Groupe CRM en Sciences des Radiations, Faculté de médecine, Université de Sherbrooke, Sherbrooke, Québec.J1H 5N4, Canada

${ }^{d}$ Institute Pluridisiplinaire Hubert Curien, 23 rue du Loess, 67037 Strasbourg Cedex 2, France

${ }^{\mathrm{e}}$ Graduate School of Maritime Sciences, Kobe University, 5-1-1 Fukaeminami-machi, Higashinada-ku, 658-0022 Kobe, Japan

\begin{abstract}
The aim of the present study is to evaluate the mechanisms by which secondary electrons of low energy degrade poly(allyl diglycol carbonate) (PADC) when it is used as a Solid State Nuclear Track Detector. We measured by time of flight mass spectrometry, the positive and negative ions desorbed by the impact of 5-30 eV electrons on three monolayer thick films of various PADC surrogate molecules, which contained ether and/or carbonyl $(\mathrm{C}=\mathrm{O})$ moieties. As cleavages within the molecules progress, most anion yields are seen to decrease with an increasing cumulative number of incident electrons (i.e., fluence). In contrast, the yield of $\mathrm{O}^{-}$at incident energies $>15$ $\mathrm{eV}$, which is associated with damage at a carbonyl group, increases monotonically with fluence. This finding implies that cleavage of carbonyl groups occurs after damage to other oxygen containing groups within the surrogates. The present result corroborates the previously postulated two-step degradation process in PADC irradiated with high-energy electrons and $222 \mathrm{~nm}$ UV photons. More generally, these results underline the importance of considering the role of low energy secondary electrons in the deterioration of high-sensitivity energetic particle detectors.
\end{abstract}

*Corresponding author: Michel Fromm (michel.fromm@univ-fcomte.fr) 
Table 1 List of fragments desorbed from condensed FDA, DC and DGMEA.

Figure 1 Chemical structures of (a) a repeat unit of PADC; and molecular structures of (b) formaldehyde diethyl acetal, FDA, (c) diethyl carbonate, DC, and (d) diethylene glycol monoethyl ether acetate, DGMEA.

Figure 2 The anion yields of (a) $\mathrm{H}^{-}$, (b) $\mathrm{CH}_{3}{ }^{-}$, (c) $\mathrm{O}^{-}$, (d) $\mathrm{OH}^{-}$, (e) $\mathrm{C}_{2} \mathrm{H}_{4}^{-}$, and (f) $\mathrm{C}_{2} \mathrm{H}_{5} \mathrm{O}^{-}$ as a function of the incident electron energy. Yields from FDA, DC and DGMEA are indicated respectively with circle, square and diamond symbols.

Figure 3 The cation yields of (a) $\mathrm{CH}_{3}{ }^{+}$, (b) $\mathrm{C}_{2} \mathrm{H}_{3}{ }^{+}$, (c) $\mathrm{C}_{2} \mathrm{H}_{3} \mathrm{O}^{+}$and (d) $\mathrm{C}_{2} \mathrm{H}_{3} \mathrm{O}_{2}{ }^{+}$as a function of the incident electron energy. The yields from FDA, DC and DGMEA are represented as circle, square and diamond symbols, respectively.

Figure 4 The relative anion yield of $\mathrm{CH}_{3}{ }^{-}$(open circles), $\mathrm{O}^{-}$(open triangles), $\mathrm{C}_{2} \mathrm{H}_{5} \mathrm{O}_{2}{ }^{-}$ (open squares) from DGMEA, as a function of the number of electrons. Full lines in the graph are guides for the eye.

Figure 5 The relative anion yield of $\mathrm{CH}_{3}{ }^{-}$(open circles), $\mathrm{O}^{-}$(open triangles), $\mathrm{C}_{2} \mathrm{H}_{5} \mathrm{O}_{2}{ }^{-}$ (open squares) from DGMEA, as a function of the number of incident $30 \mathrm{eV}$ electrons. Full lines in the graph are guides for the eye.

Keywords : dissociative electron attachment, low energy electrons, PADC, stimulated desorption 


\section{Introduction}

Poly(allyl diglycol carbonate), PADC, often called CR-39 ${ }^{\mathrm{TM}}$ (its trade mark "Columbia Resin \#39") is considered as the most sensitive Solid State Nuclear Track Detector, SSNTD. ${ }^{(1),(2)}$ Unlike other SSNTDs, PADC can detect energetic protons (and neutron recoil nuclei) as well as heavy ions, in mixed radiation fields without background noise. Due to this advantage, it has been utilized in diverse applications, such as space radiation dosimetry ${ }^{(3)-(5)}$ and laser driven ion acceleration experiments. ${ }^{(6),(7)}$ At least six books have been dedicated to SSNTD applications. ${ }^{(8)-(13)}$ Beginning in the 1990s, molecular damage (i.e., loss/generation of chemical functions) within PADC has been examined using FT-IR spectrometric methods for a wide range of stopping powers, specifically from 1.2 to $12,000 \mathrm{eV} / \mathrm{nm},{ }^{(14)-(15)}$ with a view to developing new SSNTD materials with desired track registration sensitivity from the viewpoint of molecular re-arrangement. Figure 1 (a) represents a repeat unit of PADC, which contains the radiation-sensitive moieties of an ether in the center and two carbonate esters in symmetrical positions. Such radiation-sensitive moieties are connected by "polyethylene-like" networks formed during the polymerization, which are considered as the radiation-tolerant moiety of the polymer. ${ }^{(17)}$

From a complete analysis of the existing available data, ${ }^{(14)-(15)}$ a two-step damage formation model of the latent track in PADC was deduced. This mechanism supposes that the carbonate ester can only be lost on the ester in the same PADC unit. ${ }^{(18)}$ Based on the conventional track-overlapping model, which expresses the distribution of ion tracks using random numbers, we clarified that at least two electron hits are required to break the carbonate ester in PADC. ${ }^{(18)}$ Indeed, it was quantitatively observed that the damage to PADC irradiated with protons and heavy ions follows a mechanism in which the amount of ether lost is always greater than that of carbonate ester and other functional groups. To further investigate this hypothesis and determine the mechanisms of PADC degradation, we measured the damage induced by low-energy electrons (LEEs, $5-30 \mathrm{eV}$ ) to surrogates of PADC. Since LEEs are produced in large numbers in organic media $\left(\sim 340,000 / \mathrm{MeV}\right.$ of deposited primary energy), ${ }^{(19)}$ we expect their interactions and the damage they induce in PADC to be significant and related to the mechanisms of degradation. In fact, the large amount of LEEs produced around the track of energetic protons in PADC has recently been determined by computer simulations. $^{(20)}$

In the present study, we investigated damage to hydrocarbon molecules condensed as thin films on a metal substrate in ultra-high vacuum (UHV). The measurements were performed by measuring desorption of negative and positive ions, 
induced by electrons impinging on the films with energies between 5 and $30 \mathrm{eV}$. Since neither PADC nor diethyleneglycol bis allyl carbonate, (i.e. the monomer in PADC) are sufficiently volatile to be introduced as vapors into the apparatus, the electron stimulated desorption (ESD) currents were recorded with films made of condensed surrogates of PADC. We also note that previous anion ESD experiments have shown that LEEs induce $\mathrm{C}-\mathrm{O}$ and $\mathrm{C}-\mathrm{H}$ bond cleavages in small ethers and hydrocarbon molecules. $^{(22),(21)}$

\section{Experimental section}

\subsection{Materials}

The surrogates of PADC, whose nomenclatures are presented in Fig.1 (b), (c) and (d), are formaldehyde diethyl acetal (FDA), diethyl carbonate (DC) and diethylene glycol monoethyl ether acetate (DGMEA), all of which were obtained from SIGMA-ALDRICH Co. LLC. Two ethers, methylene and ethyl groups compose FDA. In contrast, DC contains only a carbonate ester groups in its center. DGMEA contains both radio-sensitive moieties of ether and carbonate groups which are separated by ethyl groups.

\subsection{LEE irradiation and TOF mass spectrometry}

For each target, three monolayers of a particular surrogate molecule were condensed into three monolayers on a platinum substrate held at $50 \mathrm{~K}$ in a stainless steel UHV chamber pumped to $2 \times 10^{-10}$ Torr installed in Sherbrooke University, Canada. (23),(24) LEE irradiations were performed with a pulsed electron beam (Current: $1.1 \mathrm{nA}$, Beam size: $3 \pm 0.5 \mathrm{~mm}^{2}$ ) by a Kimball Physics ELG-2 electron gun. Electrons impinged onto the molecules at an incident angle of $45^{\circ}$ from the substrate normal. The desorbed ions yields were measured as functions of incident electron energy (ion yield functions) by recording mass spectra for $10^{5}$ electron pulses (equivalent to $1.4 \times 10^{11}$ electrons) at incrementally increasing incident electron energies with steps of $0.25 \mathrm{eV}$. To minimize the effects of sample charging, yield functions were recorded for $5-15 \mathrm{eV}$ on one film, and then, for $15-30 \mathrm{eV}$ on another. Desorbed fragments were injected into a time of flight (TOF) mass spectrometer (Kore Technology R-500) to record the yields and mass to charge ratios $(\mathrm{m} / \mathrm{z})$ of desorbed anions and cations. ${ }^{(24)}$

\section{Results and discussion}

In the present ESD experiments, desorption of anions essentially stems from two distinct processes: dissociative electron attachment (DEA) and dipolar dissociation (DD). DEA to a molecular target $A B$ can be represented as, ${ }^{(25)}$ 
$A B+e^{-} \rightarrow A B^{*-} \rightarrow A^{-}+B$

where $A B^{*}$ is the intermediate transient anion, which dissociates into a stable anion $A^{-}$ and a neutral species $B$ within a short lifetime of the order of a vibrational period of $A B^{{ }^{*}}$. DEA is a resonant scattering process due to involvement of the transient (compound) anion state formed by both the molecule and incident electron. The DD process corresponds to the following reaction scheme, ${ }^{(25)}$

$$
A B+e^{-} \rightarrow A B^{*}+e^{-} \rightarrow A^{-}+B^{+}+e^{-}
$$

In $\mathrm{DD}$, the electronically excited molecule fragments into an ion pair of $A^{-}$and $B^{+}$. The cross section for the DD process is usually non-resonant and hence increases monotonically with electron energy; i.e., in our data, from threshold (12 - $15 \mathrm{eV})$ to maximum values at higher energies between $\sim 50$ and $\sim 100 \mathrm{eV}$. ${ }^{(25)}$ The desorption of cationic fragments also proceeds by dissociative ionization (DI) via excitation of dissociative molecular cationic states of the molecule, i.e., $A B+e^{-} \rightarrow A+B^{+}+2 e^{-}$

Threshold energies for the DI process will be higher than for DD by at least the electron affinity of the electronegative fragment $A$; maximum yields are observed at similar energies to DD processes. DD and DI processes by electronic excitation are examples of non-resonant scattering processes.

Desorbed negative and positive fragments are listed in Table 1. Some examples of anion and cation yield functions are illustrated in Fig. 2 and in Fig. 3, respectively. Circle, square and diamond symbols indicate, respectively, the anion and cation yields from FDA, DC and DGMEA. The yields of $\mathrm{H}^{-}(m / z=1)$ are at least three orders of magnitude higher than all other anions, consistent with previous results based on condensed hydrocarbon targets. ${ }^{(21)(21)}$ Yields of $\mathrm{CO}^{-}$or $\mathrm{CO}_{2}^{-}(\mathrm{m} / \mathrm{z}=28$ or 44$)$, whose neutral forms are known to originate from the segmentation of carbonate ester groups ${ }^{(26)}$ were not observed for any target molecule ${ }^{(27),(28)}$, due to the negative electron affinities of $\mathrm{CO}$ and $\mathrm{CO}_{2}$ ground states. ${ }^{(28)}$ Since the detection probabilities of the ions vary with their mass, momentum and their interactions in the film prior to desorption, ${ }^{(23),(24)}$ it is not possible to infer relative cross sections for ion production from the measured ion yield. The anion yields of $\mathrm{CH}_{3}{ }^{-}(\mathrm{m} / z=15)$ are represented as a function of the incident electron energy in Fig. 2 (b). Most likely, the $\mathrm{CH}_{3}{ }^{-}$originates from cleavages at the positions labeled "1" in Fig.1. $\mathrm{CH}^{-}$and $\mathrm{CH}_{2}{ }^{-}(\mathrm{m} / z=13$ or 14$)$ are also observed and may originate from proton transfer during the same DEA process that generates the $\mathrm{CH}_{3}$ moiety. In Fig. 2 (b), we observe DEA resonances at $9.0 \mathrm{eV}$, that can be assigned to the decay of core-excited transient anions. ${ }^{(25)}$ Above $15 \mathrm{eV}$, the recorded monotonic increase of the yields corresponds to DD. Similar trends are observed in the anion yield 
functions of $\mathrm{H}^{-}, \mathrm{C}_{2} \mathrm{H}_{4}^{-}$, and $\mathrm{C}_{2} \mathrm{H}_{5} \mathrm{O}^{-}(\mathrm{m} / \mathrm{z}=1,28$, and 45$)$.

In contrast to the high anion yields of $\mathrm{H}^{-}$, the cation signal of $\mathrm{H}^{+}$is barely observable. No noticeable structures are seen in the cation yield function of $\mathrm{CH}_{3}{ }^{+}$(Fig. 3 (a)), whose amplitude rises significantly above $18 \mathrm{eV}$. The behavior of $\mathrm{CH}_{3}{ }^{+}$yield function is almost identical to those of all other cations, as depicted in Fig. 3 (b), (c) and (d). Judging from these trends, it can be concluded that the threshold of DD lies between 15 and $18 \mathrm{eV}$. We also observe a clear peak in the anion yield function of $\mathrm{O}^{-}$ $(\mathrm{m} / \mathrm{z}=16)$ from $\mathrm{DC}$ at $9.5 \mathrm{eV}$ (Fig. 2 (c)). On the other hand, the $\mathrm{O}^{-}$yield functions from FDA and DGMEA do not exhibit noticeable resonances. Moreover, the $\mathrm{O}^{-}$yield from FDA does not rise significantly above $16 \mathrm{eV}$. Thus while $\mathrm{O}^{-}$anions desorption from ethers in FDA is barely detected, the release fragments with $m / z=25,26,27,28$, $29,41,43$ and 45 from FDA reveals significant ether damage. In contrast, we observe a drastic increase of the $\mathrm{O}^{-}$yield from DGMEA above $\sim 15 \mathrm{eV}$ incident electron energy. Therefore, $\mathrm{O}^{-}$desorption from DGMEA arises from electronic excitation of the double bond in location labeled " 2 ", which has no analog in FDA. The yield function of $\mathrm{OH}^{-}$ $(m / z=17)$ is also seen in Fig. 2 (d). In the $\mathrm{OH}^{-}$yield function, the resonances are observed around $10 \mathrm{eV}$ and a monotonic rise in yield is confirmed above $15 \mathrm{eV}$. Qualitatively speaking, desorption of $\mathrm{OH}^{-}$are fairly low compared to those of other anions. The desorption of $\mathrm{OH}^{-}$from these molecules suggests that some rearrangement or "scrambling" during dissociation is possible, for example to allow proton transfer from a carbon atom to a departing $\mathrm{O}^{-}$ion. The formation of $\mathrm{OH}^{-}$by the reactive scattering of $\mathrm{O}^{-}$in hydrocarbon containing films has also been reported. ${ }^{(30)} \mathrm{In}$ such cases nevertheless, $\mathrm{OH}^{-}$yield was significantly smaller (i.e., $<10 \%$ ) that of the $\mathrm{O}^{-}$ signal.

In previous experiments with UV photons at a wavelength of $222 \mathrm{~nm}$, decarboxylation accompanied by the release of $\mathrm{CO}$ and $\mathrm{CO}_{2}$ gas was observed by IR spectroscopy along with the loss of carbonyl signal in PADC. ${ }^{(31)}$ It was additionally found that carbonyl groups were not cleaved until neighboring ether or $\mathrm{C}-\mathrm{O}-\mathrm{C}$, which composes carbonate ester, were damaged. In the present study, due to the variety of fragment desorbed, especially at masses $\geq 25 \mathrm{amu}$, it seems likely that carbonyl moieties are once again only damaged after cleavages of the ether or ester in the same molecule has occurred.

As mentioned above, the desorption yields of $\mathrm{O}^{-}$and $\mathrm{OH}^{-}$from DGMEA are barely detected for electron energies below $15 \mathrm{eV}$. Thus, we can say that desorption of $\mathrm{O}^{-}$is due to $\mathrm{DD}$ at the carbonyl. To test that hypothesis, we investigated the variation of anion yields with electron exposure to at two particular energies. Figure 4 and 5 show 
how the yields of $\mathrm{CH}_{3}^{-}$, $\mathrm{O}^{-}$and $\mathrm{C}_{2} \mathrm{H}_{3} \mathrm{O}_{2}{ }^{-}$desorbed from DGMEA vary during extended electron irradiation at incident electrons with energies of 9 and $30 \mathrm{eV}$, respectively (i.e. below and above the DD threshold). In the figures, the yields are normalized to their initial values, obtained after exposure to $1.4 \times 10^{11}$ electrons. When samples are exposed to electrons at $9 \mathrm{eV}$, the anion yields of $\mathrm{CH}_{3}{ }^{-}, \mathrm{O}^{-}$and $\mathrm{C}_{2} \mathrm{H}_{3} \mathrm{O}_{2}{ }^{-}$are observed to decrease slightly during prolonged irradiation (Figure 4). When samples are exposed to electrons at $9 \mathrm{eV}$, the anion yields of $\mathrm{CH}_{3}{ }^{-}, \mathrm{O}^{-}$and $\mathrm{C}_{2} \mathrm{H}_{3} \mathrm{O}_{2}{ }^{-}$are observed to decrease slightly during prolonged irradiation (Figure 4). This small decrease in signal likely reflects the gradual loss of intact DGMEA molecules from the film (and more specifically near the film/vacuum interface, where most desorbed ions originate). Much more pronounced decreases in desorption signal are reported in Fig. 5 for $\mathrm{CH}_{3}{ }^{-}$and $\mathrm{C}_{2} \mathrm{H}_{3} \mathrm{O}_{2}{ }^{-}$fragments from films under electron irradiation at $30 \mathrm{eV}$ (Figure 5). Once again, this decrease is plausibly related to the depletion within the film of intact molecules of fragments capable of dissociating to produce these anions. However, at $30 \mathrm{eV}$, net positive sample charging is possible due to ionization occurring within the film, secondary electron emission, and the trapping of cations formed by DI and DD. Such charging would act to hamper the desorption of low kinetic energy anions. However, similar behaviors under electron bombardment of the normalized $\mathrm{CH}_{3}{ }^{-}$and $\mathrm{C}_{2} \mathrm{H}_{3} \mathrm{O}_{2}{ }^{-}$desorption signals (Figure 5) suggest that the depletion of intact DGMEA molecules must be the favored explanation for the observed decrease with fluence. These signals surely derive from close to the ends of the DGMEA molecule, by scission of bonds 1 (or 11) and 4 (see Figure $1(\mathrm{~d})$ ). The kinetic energies of these fragment ions are likely different; if film charging were the cause of their variation with fluence, then it would me most surprising for them to behave so similarly.

In contrast to the other signals reported in Fig. 5, the relative yield of $\mathrm{O}^{-}$rises monotonically with increasing exposure to $30 \mathrm{eV}$ electrons. This specific behavior indicates that some electron-induced modification of molecules in the sample produces new species in the film, for which the probability of $\mathrm{O}^{-}$desorption at $30 \mathrm{eV}$ is sufficiently greater than for intact DGMEA. Such a behavior demonstrates that cleavages of carbonyl are promoted by longer exposure times (i.e. by increasing the probability that an electron hit has already occurred elsewhere in the molecules). In addition, we can deduce from this analysis that at least two electrons are required to damage the carbonyl group in DGMEA. Following initial electron-induced damage, heavy fragment species remaining in the film are subsequently excited by other incident electrons, leading to carbonyl breakage in DGMEA. Therefore, it is highly probable that the ester in DGMEA is cleaved after damage to the ether. The present result confirms 
the previously suggested two-step damage formation model deduced from FT-IR measurements. ${ }^{(18)}$ This strongly corroborates the concept that the number of LEEs, which hit a molecule, may represent an appropriate parameter to describe the damage formation process of PADC and more generally in polymers.

\section{Conclusion}

In the present study, we investigated the role played by low energy secondary electrons, in the creation of latent tracks in PADC. For this purpose, we measured by TOF mass spectrometry the electron stimulated desorption of anions and cations from multilayer films of three different PADC surrogates FDA, DC and DGMEA. With the exception of $\mathrm{O}^{-}$desorption from FDA and DGMEA, the anion yield functions from these films exhibited resonance near $9 \mathrm{eV}$. That could be assigned to DEA. In contrast, the only $\mathrm{O}^{-}$yield function showing a resonance at this energy arises from DC, i.e., no resonance feature is apparent in measurements for FDA and DGMEA. The anion yields of $\mathrm{O}^{-}$from $\mathrm{DC}$ and DGMEA increase monotonically with incident electron energies above $15 \mathrm{eV}$, where molecular cleavages are governed mainly by $\mathrm{DD}$. The $\mathrm{O}^{-}$yield from FDA, which does not contain the carbonyl group, was very low and almost constant over the entire energy range. We therefore surmise that desorption of $\mathrm{O}^{-}$from DGMEA above $15 \mathrm{eV}$ is essentially due to DD at the carbonyl. Additionally, we measured the variation of fluence, at 9.0 and $30 \mathrm{eV}$, i.e., at electron impact energies lying respectively below and above the energetic threshold for DD. When DGMEA was irradiated with $9 \mathrm{eV}$ electrons, the anion yields of $\mathrm{CH}_{3}{ }^{-}, \mathrm{O}^{-}$and $\mathrm{C}_{2} \mathrm{H}_{3} \mathrm{O}_{2}{ }^{-}$decreased with the number of incident electrons. As the number of $30 \mathrm{eV}$ electrons increased, the relative anion yields of $\mathrm{CH}_{3}{ }^{-}$and $\mathrm{C}_{2} \mathrm{H}_{3} \mathrm{O}_{2}{ }^{-}$also decreased. In contrast, the yield of $\mathrm{O}^{-}$ increased significantly with fluence. This behavior supports the previously proposed degradation mechanism postulated from the results obtained by FT-IR spectrometry of PADC irradiated with $28 \mathrm{MeV}$ electrons and $222 \mathrm{~nm}$ UV photons. In fact, the ensemble of our results confirm the previously suggested two-step damage formation model deduced from FT-IR measurements. They validate the concept that the number of LEEs, which hit a molecule, may represent an appropriate parameter to describe the details of damage formation in a latent track of PADC, and more generally of polymers, when such compounds are exposed to high-energy radiations.

For a more detailed understanding of the mechanism of latent track formation in PADC, it may be possible to use the DD related $\mathrm{O}^{-}$desorption signal from DGMEA at $30 \mathrm{eV}$, and so probe such processes at electron energies below the threshold for anion 
desorption at $\sim 5 \mathrm{eV}$, for example via low lying shape resonances. A similar approach has been used to monitor damage in $\mathrm{CF}_{2} \mathrm{Cl}_{2}$ and $\mathrm{CH}_{3} \mathrm{COH} .{ }^{(31)}$ Alternatively, changes in high-resolution-electron-energy-loss vibrational or electronic spectra may provide useful information. ${ }^{(31)}$ Finally, we note that the radical and ions created by the LEEs may undergo subsequent chemical reactions (e.g. in the case of water radiolysis see Marignier et al.). ${ }^{(31)}$

Acknowledgements

This study was supported by the JSPS KAKENHI Grant Number 16K05002, the Canadian Institutes of Health Research (MOP81356) and the funds of Kobe University for the cotutelle program with the Université de Strasbourg.

\section{References}

(1) Cartwright, B.G.; Shirk, E.K.; Price, P.B.; A nuclear-track-recording polymer of unique sensitivity and resolution. Nucl. Instrum. Meth. B 1978, 41, 447-460.

(2) Fleischer, R.L.; Price, P.B.; Walker, R.M.; Nuclear Tracks in Solids: Principles and Applications; University of California Press, 1975.

(3) Doke, T.; Hayashi, T.; Nagaoka, S.; Ogura, K.; Takeuchi, R.; Estimation of dose equivalent in STS-47 by combination of TLDs and CR-39. Radiat. Meas. 1995, 24, 75-82.

(4) Benton, E.R.; Benton, E.V.; Frank; A.L.; Passive dosimetry aboard the Mir Orbital Station: internal measurements. Radiat. Meas. 2002, 35, 439-455.

(5) Kodaira, S., Yasuda, N., Kawashima, H., Kurano, M., Hasebe, N., Doke, T., Ota, S., Ogura, K.; Control of the detection threshold of CR-39 PNTD for measuring ultra heavy nuclei in galactic cosmic rays. Radiat. Meas. 2009, 44, 861-864.

(6) Fukuda, Y.; Faenov, A.Ya.; Tampo, M.; Pikuz, T.A.; Nakamura, T.; Kando, M.; Hayashi, Y.; Yogo, A.; Sakaki, H.; Kameshima, T. et al.; Energy Increase in Multi-MeV Ion Acceleration in the Interaction of a Short Pulse Laser with a Cluster-Gas Target. Phys. Rev. Lett. 2009, 103, 165002.

Kanasaki, M.; Jinno, S.; Kondo, K.; Oda, K.; Yamauchi, T; Fukuda, Y.; The precise energy spectra measurement of laser-accelerated $\mathrm{MeV} / \mathrm{n}$-class high-Z ions and protons using CR-39 detectors. Plasma Phys. Control. Fusion 2016, 58, 034013.

(8) Durrani, S.A.; Bull, R.K.; Solid State Nuclear Track Detection: Principles, 
Methods and Applications, Pergammon Press; U.K., 1987.

(9) Durrani, S.A.; Ilic, R.; Radon Measurements by Etched Track Detectors, Applications in Radiation Protection, Earth Science and the Environment; Singapore, 1997.

(10) Fink, D.; Fundamentals of Ion-Irradiated Polymers, Springer-Verlag; Berlin, Heidelberg, New York, 2004.

(11) Sidorov, M.; Ivanov, O.; Nuclear Track Detectors; Design, Methods and Applications, Nova Science Publishers, 2010.

(12) Spohr, R.; Ion Tracks and Microtechnology, Principles and Applications, Vieweg, Braunschweig, 1990.

(13) Zhou, D.; CR-39 Plastic Nuclear Track Detectors in Physics Research, Nova Science Publishers, 2012.

(14) Yamauchi, T.; Studies on the nuclear tracks in CR-39 plastics. Radiat. Meas. 2003, 36, 73-81.

(15) Mori, Y.; Yamauchi, T.; Kanasaki, M.; Maeda, Y.; Oda, K.; Kodaira, S.; Konishi, T.; Yasuda, N.; Barillon, R.; Radiation chemical yields for loss of ether and carbonate ester bonds in PADC films exposed to proton and heavy ion beams. Radiat. Meas. 2011, 46, 1147-1153.

(16) Kusumoto, T.; Mori, Y.; Kanasaki, M.; Ikenaga, R.; Oda, K.; Kodaira, S.; Kitamura, H.; Barillon, R.; Yamauchi, T.; Radiation chemical yields for the losses of typical functional groups in PADC films for high energy protons registered as unetchable tracks. Radiat. Meas. 2015, 87, 35-42.

(17) O'Donnell, J. H.; Radiation Chemistry of Polymers. The Effects of Radiation on High-Technology Polymers. Chapter 1, ACS Symposium Series 1989, 1-13.

(18) Kusumoto, T.; Mori, Y.; Kanasaki, M.; Oda, K.; Kodaira, S.; Honda, Y.; Tojo, S.; Barillon, R.; Yamauchi, T.; Sudden increase of the radiation chemical yield for loss of carbonate ester in PADC detector where the track overlapping of $28 \mathrm{MeV}$ electrons becomes significant. JPS Conf. Proc. 2016, 11, 010001.

(19) Pimblott, S.M.; Laverne, J.A.; Production of low-energy electrons by ionizing radiation. Radiat. Phys. Chem. 2007, 76, 1244-1247.

(20) Fromm, M.; Quinto, M.A.; Weck, P.F.; Champion, C.; Low energy electrons and swift ion track structure in PADC. Radiat. Phys. Chem. 2015, 115, 36-42.

(21) Rowntree, P.; Parentau, L.; Sanche, L.; Anion yields produced by low-energy electron impact on condensed hydrocarbon films, J. Phys. Chem. 1991, 95, 4902-4909.

(22) Bogdan, C.I.; Michael, A.; A dramatic difference between the electron-driven 
dissociation of alcohols and ethers and its relation to Rydberg states, Phys. Chem. Chem. Phys. 2008, 10, 5232-5237.

(23) Hedhili, M.N.; Cloutier, P.; Bass, A.D.; Madey, T.E.; Sanche, L.; Electron stimulated desorption of anionic fragments from films of pure and electron-irradiated thiophene. J. Chem. Phys. 2006, 125, 94704.

(24) Bazin, M.; Ptasińska, S.; Bass, A.D.; Sanche, L.; Electron induced dissociation in condensed-phase nitromethane I: desorption of ionic fragments. Phys. Chem. Chem. Phys. 2009, 11, 1610-1618.

(25) Bass, A.D.; Sanche, L.; in "Charge particle ant photon interactions with matter: Chemical, physicochemical and biological consequences with applications", ed Y. Hatano and A. Mozumder, Marcel Dekker Inc., 2004.

(26) Yamauchi, T.; Barillon, R.; Balanzat, E.; Asuka, T.; Izumi, K.; Masutani, T.; Oda, K.; Yields of $\mathrm{CO}_{2}$ formation and scissions at ether bonds along nuclear tracks in CR-39, Radiat. Meas. 2005, 40, 224-228.

(27) Lepage, M.; Michaud, M.; Sanche, L.; Low-energy electron scattering cross section for the production of $\mathrm{CO}$ within condensed acetone, J. Chem. Phys. 2000, $113,3602-3608$.

(28) Orzol, M.; Sedlacko, T.; Balog, R.; Langer, J.; Karwasz, G.P.; Illenberger, E.; Lafosse, A.; Bertin, M.; Domaracka, A.; Azria, R.; Reactions in nanofilms of trifluoroacetic acid $\left(\mathrm{CF}_{3} \mathrm{COOH}\right)$ driven by low energy electrons, Int. J. Mass Spectrum. 2006, 254, 63-69.

(29) Meunier, M.; Quirke, N.; Binesti, D.; The Calculation of the Electron Affinity of Atoms and Molecules. Molecules. Mol. Simul. 1999, 23, 109-125.

(30) Kühn, A.; Fenzlaff, H.P; Illenberger, E.; Formation and Dissociation of Negative-Ion Resonances in Methanol and Allylacohol, J. Chem. Phys. 1988, 88, 7453-7458.

(31) Sakamoto, A.; Mori, Y.; Kanasaki, M.; Yamauchi, Y.; Oda, K.; Quantum yields for loss of carbonate ester bonds in polymeric nuclear track detectors under $222 \mathrm{~nm}$ UV radiation. Review of Graduate School of Maritime Sciences, Kobe University 2010, 7, 87-98 (written in Japanese).

(32) Bass, A.D.; Arumainayagam, C.R; Sanche, L.; Revisiting the electron stimulated desorption of anions from thin films of $\mathrm{CF}_{2} \mathrm{Cl}_{2}$, Int. J. Mass Spectrom. 2008, 277, 251-255.

(33) Boyer, M.C.; Boamah, M.D.; Sullivan, K.K.; Arumainayagam, C.R.; Bazin, M.; Bass, D.D.; Sanche, L.; Dynamics of dissociative Electron-Molecule Interactions in Condensed Methanol, J. Phys. Chem. C 2014, 118, 22592. 
(34) Breton, S.-P.; Michaud, M.; Jäggle, C.; Swiderek, P.; Sanche, L.; Damage induced by low-energy electrons in solid films of tetrahydrofuran, J. Chem. Phys. 2004, 121, 11240.

(35) Marignier, J.-L.; Torche, F.; Caër, S. L.; Mostafavi, M. ; Belloni, J.; Picosecond Pulse Radiolysis of Propylene Carbonate as a Solute in Water and as a Solvent, J. Phys. Chem. B 2016, 120,2388 
Table 1

\begin{tabular}{|c|c|c|c|c|c|}
\hline \multirow[t]{2}{*}{$m / z$} & \multicolumn{2}{|c|}{ Composition } & \multicolumn{3}{|c|}{$\begin{array}{c}\text { Condensed monomers } \\
\text { (Position of cleavage in Fig. 1) }\end{array}$} \\
\hline & Negative & Positive & FDA (b) & $\mathrm{DC}(\mathrm{c})$ & $\operatorname{DGMEA}(\mathrm{d})$ \\
\hline 1 & $\mathrm{H}^{-}$ & - & Yes (-) & Yes (-) & Yes (-) \\
\hline 13 & $\mathrm{CH}^{-}$ & - & Yes (1) & Yes (1) & Yes $(1,11)$ \\
\hline 14 & $\mathrm{CH}_{2}^{-}$ & - & Yes (1) & Yes (1) & Yes $(1,11)$ \\
\hline \multirow{2}{*}{15} & $\mathrm{CH}_{3}^{-}$ & - & Yes (1) & Yes (1) & Yes $(1,11)$ \\
\hline & - & $\mathrm{CH}_{3}^{+}$ & Yes (1) & Yes (1) & Yes $(1,11)$ \\
\hline 16 & $\mathrm{O}^{-}$ & - & No & Yes (4) & Yes (2) \\
\hline 17 & $\mathrm{OH}^{-}$ & - & - & - & - \\
\hline 25 & $\mathrm{C}_{2} \mathrm{H}^{-}$ & - & Yes (2) & Yes (2) & Yes (10) \\
\hline 26 & $\mathrm{C}_{2} \mathrm{H}_{2}^{-}$ & - & Yes (2) & Yes (2) & No \\
\hline \multirow{2}{*}{27} & $\mathrm{C}_{2} \mathrm{H}_{3}^{-}$ & - & Yes (2) & Yes (2) & No \\
\hline & - & $\mathrm{C}_{2} \mathrm{H}_{3}{ }^{+}$ & Yes (2) & Yes (2) & Yes (10) \\
\hline 28 & $\mathrm{C}_{2} \mathrm{H}_{4}^{-}$ & - & Yes (2) & Yes (2) & No \\
\hline 29 & - & $\mathrm{C}_{2} \mathrm{H}_{5}^{+}$ & Yes (2) & Yes (2) & Yes (10) \\
\hline \multirow{2}{*}{41} & $\mathrm{C}_{2} \mathrm{HO}^{-}$ & - & Yes (3) & Yes (3) & Yes $(3,9)$ \\
\hline & - & $\mathrm{C}_{2} \mathrm{HO}^{+}$ & Yes (3) & Yes (3) & - \\
\hline \multirow{2}{*}{43} & $\mathrm{C}_{2} \mathrm{H}_{3} \mathrm{O}^{-}$ & - & Yes (3) & Yes (3) & Yes $(3,9)$ \\
\hline & - & $\mathrm{C}_{2} \mathrm{H}_{3} \mathrm{O}^{+}$ & Yes (3) & Yes (3) & Yes (9) \\
\hline \multirow{2}{*}{45} & $\mathrm{C}_{2} \mathrm{H}_{5} \mathrm{O}^{-}$ & - & Yes (3) & Yes (3) & Yes (9) \\
\hline & - & $\mathrm{C}_{2} \mathrm{H}_{5} \mathrm{O}^{+}$ & No & No & Yes (9) \\
\hline \multirow{2}{*}{59} & $\mathrm{C}_{2} \mathrm{H}_{3} \mathrm{O}_{2}^{-}$ & - & No & No & Yes (4) \\
\hline & - & $\mathrm{C}_{2} \mathrm{H}_{3} \mathrm{O}_{2}{ }^{+}$ & No & No & Yes (4) \\
\hline
\end{tabular}


Fig. 1.

(a)

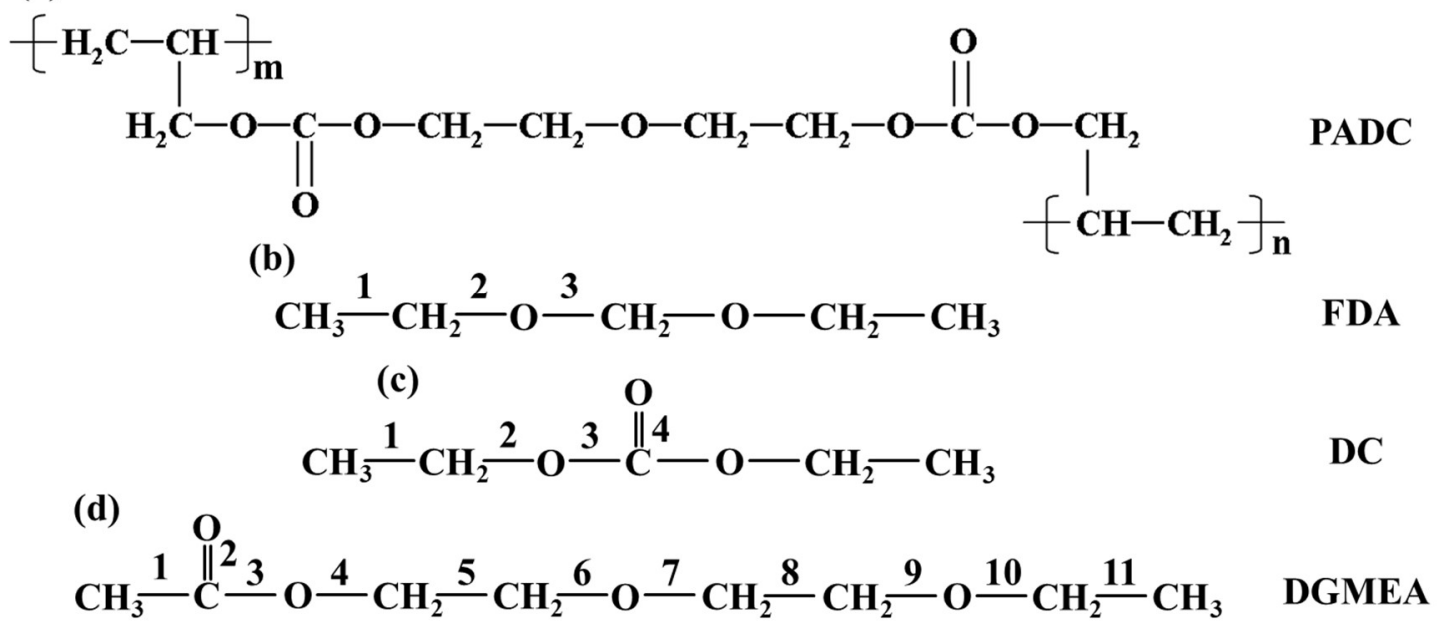


Fig. 2.

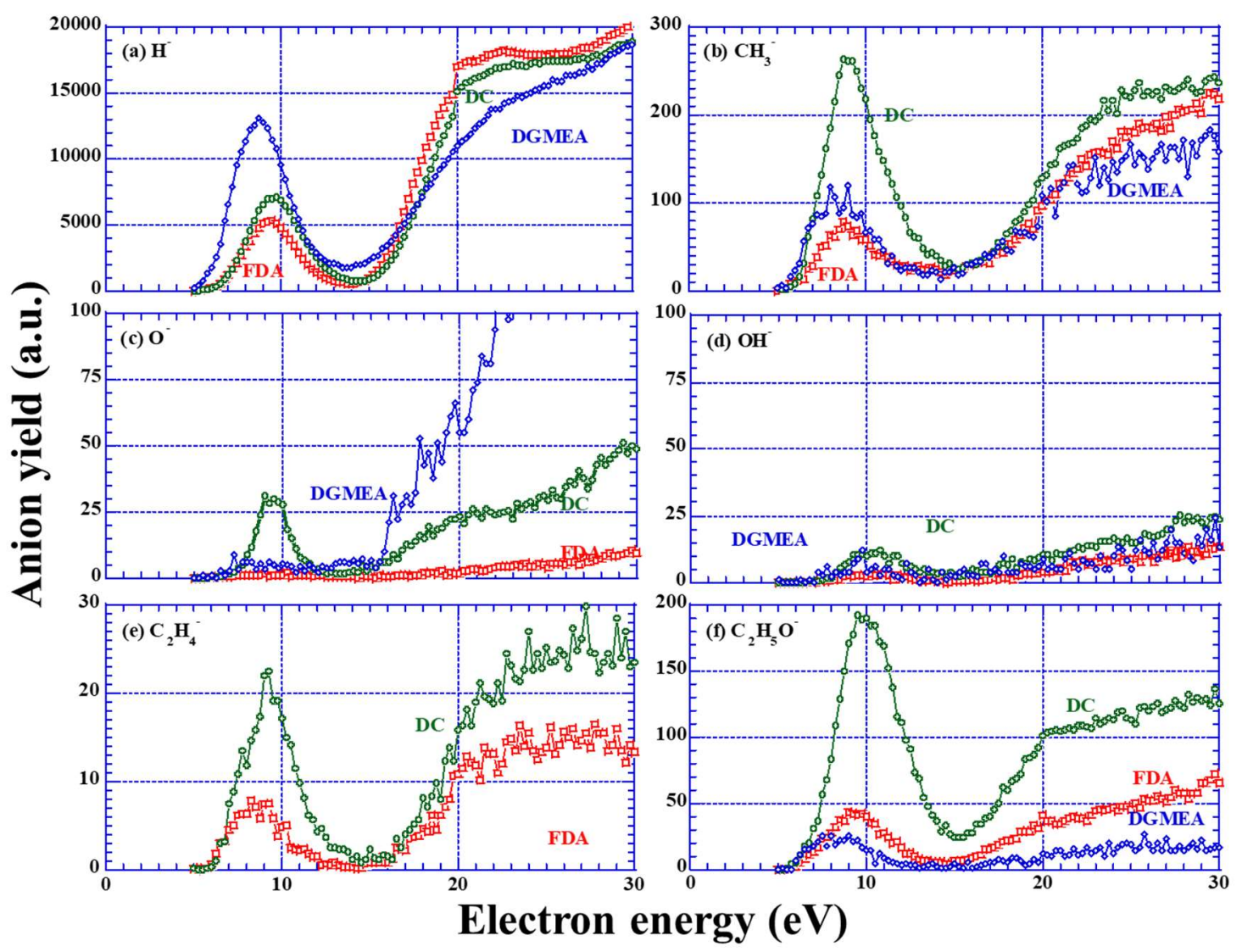


Fig. 3.

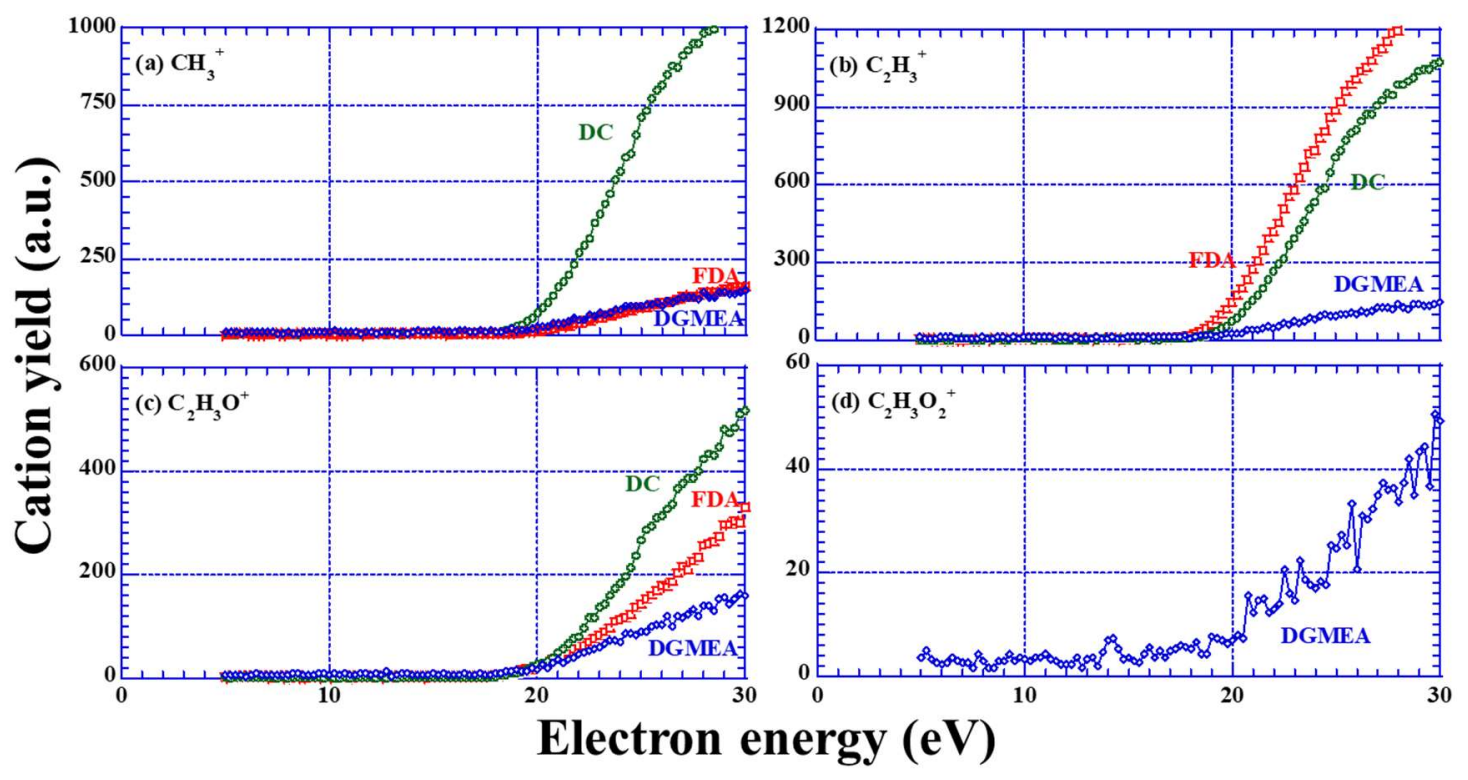


Fig. 4.

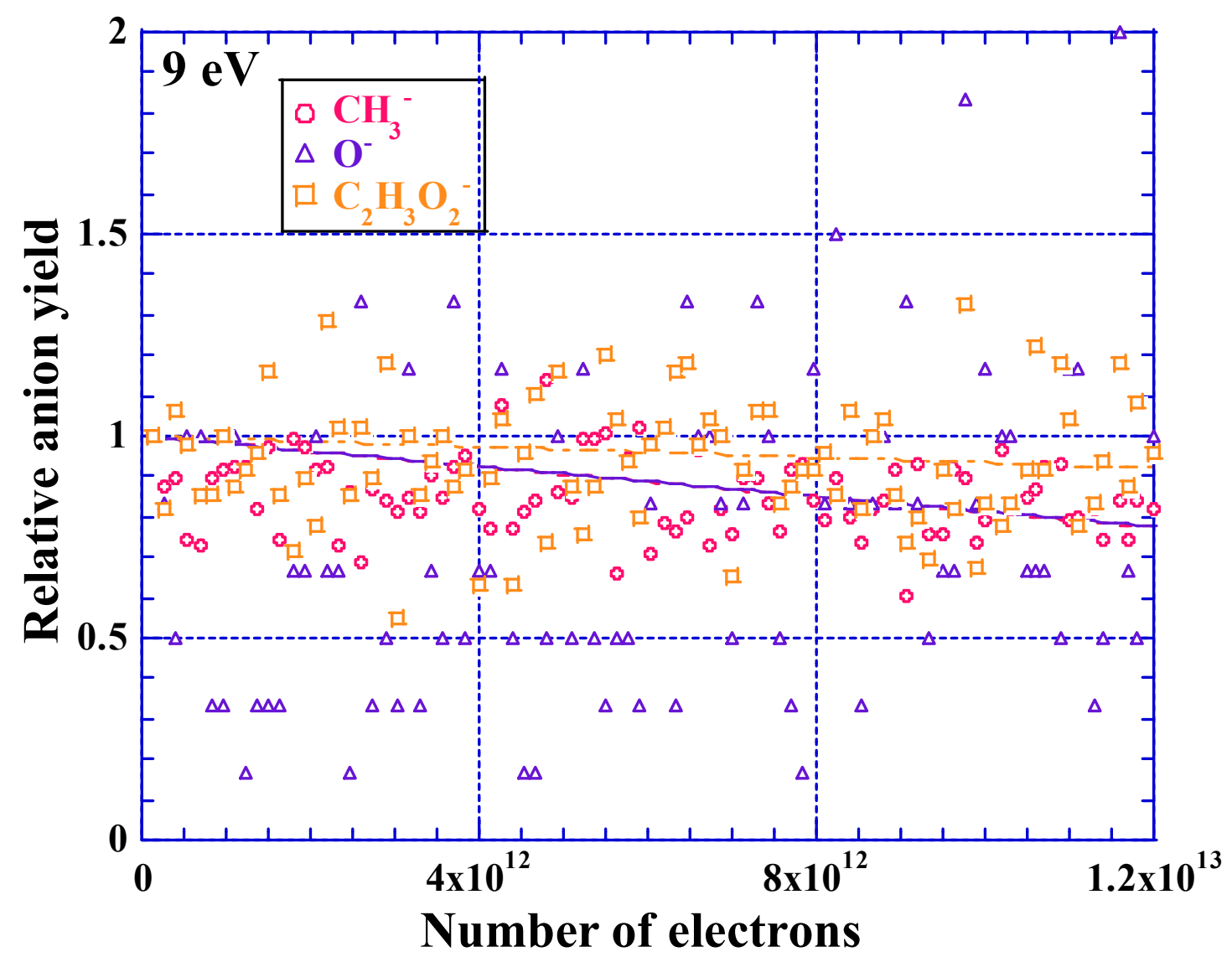


Fig. 5

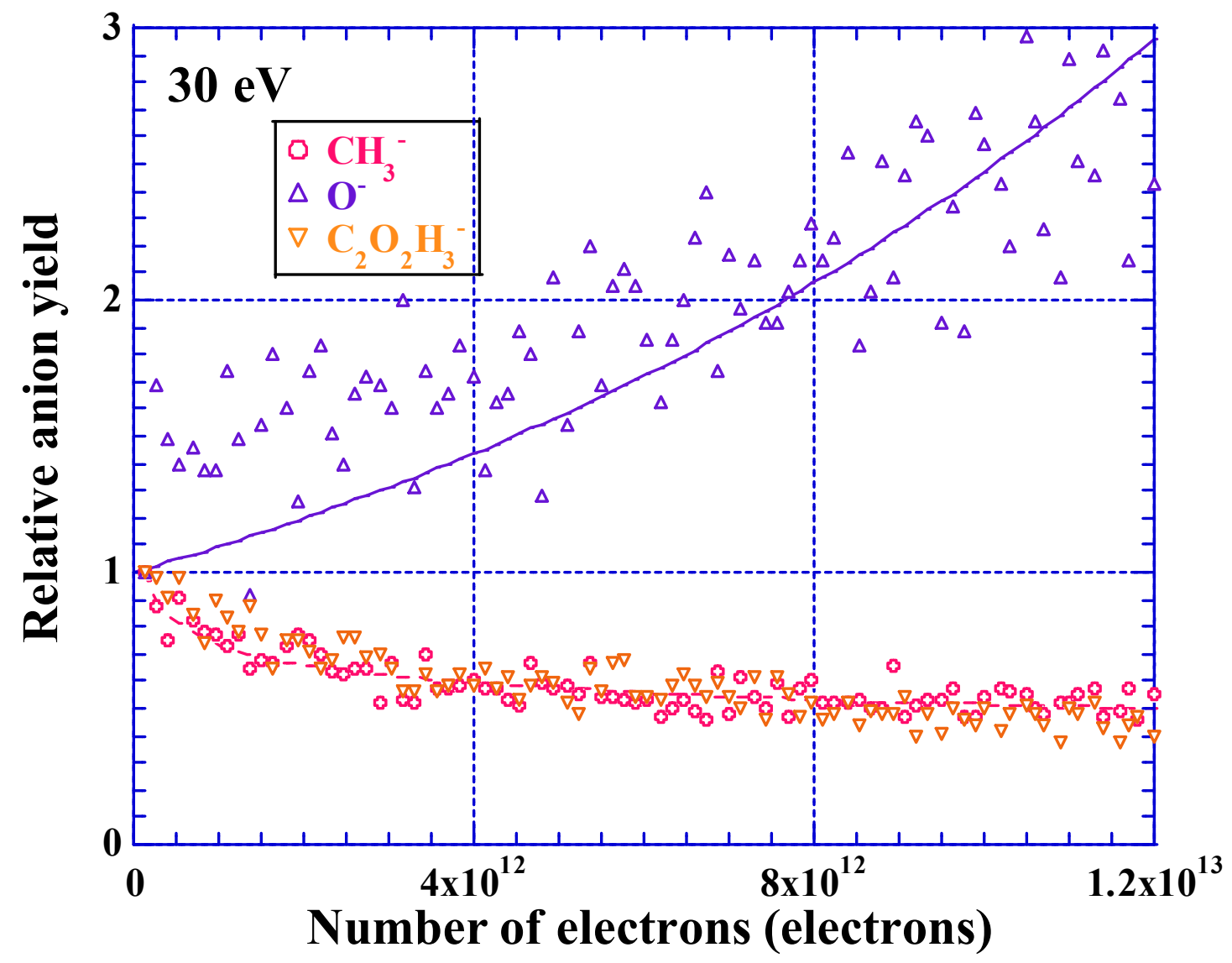


Graphical Abstract :

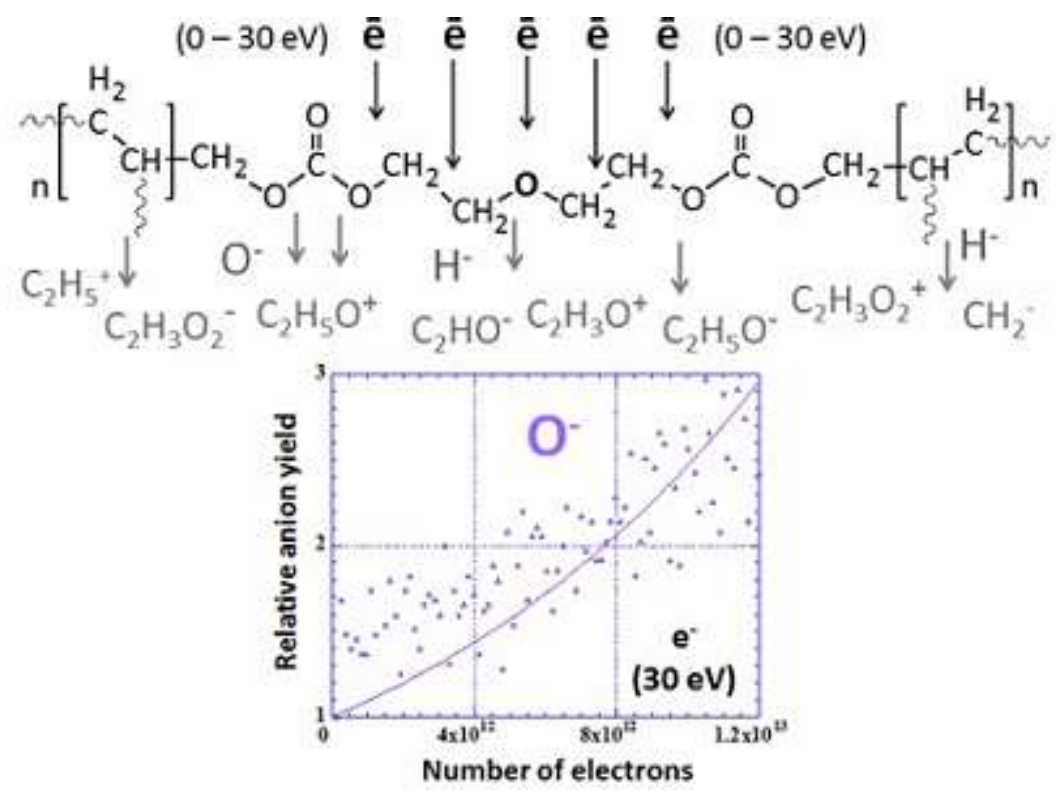

